\title{
Field calibrations of a low-cost aerosol sensor at a regulatory monitoring site in California
}

\author{
D. M. Holstius ${ }^{1}$, A. Pillarisetti ${ }^{1}$, K. R. Smith ${ }^{1}$, and E. Seto ${ }^{2}$ \\ ${ }^{1}$ University of California, Berkeley, USA \\ ${ }^{2}$ University of Washington, Seattle, USA \\ Correspondence to: D. M. Holstius (david.holstius@berkeley.edu) \\ Received: 7 January 2014 - Published in Atmos. Meas. Tech. Discuss.: 27 January 2014 \\ Revised: 28 March 2014 - Accepted: 31 March 2014 - Published: 30 April 2014
}

\begin{abstract}
Health effects attributed to ambient fine particulate matter $\left(\mathrm{PM}_{2.5}\right)$ now rank it among the risk factors with the highest health burdens in the world, but existing monitoring infrastructure cannot adequately characterize spatial and temporal variability in urban $\mathrm{PM}_{2.5}$ concentrations, nor in human population exposures. The development and evaluation of more portable and affordable monitoring instruments based on low-cost sensors may offer a means to supplement and extend existing infrastructure, increasing the density and coverage of empirical measurements and thereby improving exposure science and control. Here, we report on field calibrations of a custom-built, battery-operated aerosol monitoring instrument we developed using low-cost, off-the-shelf optical aerosol sensors. We calibrated our instruments using $1 \mathrm{~h}$ and $24 \mathrm{~h} \mathrm{PM}_{2.5}$ data from a class III US EPA Federal Equivalent Method (FEM) $\mathrm{PM}_{2.5} \beta$-attenuation monitor in continuous operation at a regulatory monitoring site in Oakland, California. We observed negligible associations with ambient humidity and temperature; linear corrections were sufficient to explain $60 \%$ of the variance in $1 \mathrm{~h}$ reference $\mathrm{PM}_{2.5}$ data and $72 \%$ of the variance in $24 \mathrm{~h}$ data. Performance at $1 \mathrm{~h}$ integration times was comparable to commercially available optical instruments costing considerably more. These findings warrant further exploration of the circumstances under which this class of aerosol sensors may profitably be deployed to generate improved $\mathrm{PM}_{2.5}$ data sets.
\end{abstract}

\section{Introduction}

The health effects attributed to outdoor fine particulate matter $\left(\mathrm{PM}_{2.5}\right)$ rank it among the risk factors with the highest health burdens in the world, annually accounting for over 3.2 million premature deaths and over 76 million lost disability-adjusted life years (Brauer et al., 2011; Lim et al., 2012). In principle, increased fixed-site monitoring could improve the coverage and quality of ambient $\mathrm{PM}_{2.5}$ data sets, but the expansion of regulatory networks with current technology is hindered by resource constraints, as conventional techniques require costly equipment (Wilson et al., 2002). In the absence of empirical measurements with adequate spatiotemporal resolution, epidemiologic studies have relied upon models to downscale or interpolate available data from satellites, regulatory monitors, land use databases, and emissions inventories (Brauer et al., 2011; Jerrett et al., 2005). In studies of air pollution exposures and health effects, the resulting exposure misclassification may attenuate or bias estimates of health effect relationships. Coarsely resolved $\mathrm{PM}_{2.5}$ monitoring data also hinders scientific understanding of fluxes resulting from urban emissions, atmospheric transformations, and transport mechanisms. Finally, the relative lack of affordable instrumentation also inhibits timely, empirical verifications of policy-based interventions to reduce emissions and exposures.

Small, inexpensive, and portable devices, relying on newly available off-the-shelf sensors, may greatly improve our capacity to characterize aerosol concentrations with high spatial and temporal resolution and low system cost, especially when many such devices can be deployed concurrently. However, the utility of this approach has not been adequately 
characterized in field settings. In the remainder of this paper, we show that it is possible to generate useful and accurate estimates of hourly and daily $\mathrm{PM}_{2.5}$ concentrations at a regulatory monitoring site by combining one such sensor with other low-cost, readily available hardware. Guided by the prior work of Watson, Wilson, Chow and colleagues (Watson, 2002; Watson et al., 1998; Wilson et al., 2002, 2005; Wilson and Suh, 1997), who extensively analyzed and discussed issues in the augmentation of the then-current Federal Reference Method (FRM) $\mathrm{PM}_{2.5}$ network with continuous PM monitors, we concentrate first and foremost on demonstrating a predictive relationship between (a) the output of the sensor and (b) regulatory monitoring data that is widely relied upon in air quality regulation and epidemiology. We note that, given a predictive relationship, further work is still required to establish equivalency with $\mathrm{PM}_{2.5}$ or any other PM concentration metric. Our intention is to demonstrate "proof of concept" in a natural environment of interest, so that the findings and methodology may be extended, critiqued, and replicated by independent researchers who are interested in the utility of this class of sensors.

In this paper, we focus on field calibration at a regulatory monitoring site in Oakland, California. Previous studies by our group have used observational and experimental methods to characterize low-cost instruments incorporating repurposed smoke-detector components (Chowdhury et al., 2007; Edwards et al., 2006; Litton et al., 2004) and a consumer-oriented, laser-based particle counter (Northcross et al., 2013; Smith, 2011). Previous studies by other researchers have characterized short-term responses of relatively inexpensive optical instruments, both custom-built and commercially available, to particle-generating activities in indoor environments (Budde et al., 2012; Nafis, 2012; Olivares et al., 2012). A larger body of scientific work has compared commercially available nephelometers, particle counters, and other light-scattering instruments to reference methods (Burkart et al., 2010; Watson et al., 1998; Wilson et al., 2002) In this paper, we report results for an even lowercost instrument, based on a sensor costing approximately USD 10. We are apparently the first to evaluate such a sensor under ambient conditions at a US regulatory monitoring site, and the first to calibrate it using $24 \mathrm{~h}$ averages of $\mathrm{PM}_{2.5}$ from a reference instrument with Federal Equivalent Method (FEM) status.

\section{Experimental methods and materials}

\subsection{The PANDA platform}

To conduct our field studies, we designed a small, portable, and reconfigurable platform around a low-cost, off-the-shelf optical sensor: the Shinyei PPD42NS (Shinyei Corp, 2010). We call our platform the PANDA (Portable and Affordable Nephelometric Data Acquisition) system.

\section{Nephelometric sensor design and specifications}

The Shinyei PPD42NS sensor has a partially enclosed chamber with a single light-emitting diode, a plastic lens, and an optical receiver at a forward angle of approximately $45^{\circ}$. A removable cap makes it possible to swab residue off the lens. Air is drawn through the sensing volume by means of a convection current established by a small $0.25 \mathrm{~W}$ resistor. The resulting absence of noise from fans or pumps is an attractive feature for possible applications in household settings, but the convective mechanism makes the airflow sensitive to orientation. The flow rate and maximum size of lofted particles are not specified. Signals resulting from the detection of scattered light are passed through filtering and amplification circuitry that are externally visible on the PPD42NS, resulting in $0-5 \mathrm{~V}$ pulses of approximately $10-100 \mathrm{~ms}$ in length. Documentation posted online by the manufacturer indicates that the $30 \mathrm{~s}$ integrated duty cycle of this PWM signal increases monotonically with "cigarette smoke", with a zero intercept and a slightly sub-linear response at higher concentrations (Shinyei Corp, 2010). Hereafter, we refer to the $30 \mathrm{~s}$ integrated duty cycle as "percent full scale" (\% FS).

We programmed a microcontroller to measure \% FS by sampling the PWM signal at approximately $1 \mathrm{MHz}$, and to record the timestamped measurement to a microSD card with the aid of a real-time clock. To investigate the effects of temperature, humidity, and ambient light on the performance of the PPD42NS sensor, and to verify that our instruments remained undisturbed, upright, and unexposed to extreme conditions, we added auxiliary sensors for light, temperature, and relative humidity to the PANDAs described in this paper. All components were housed in a $12 \times 9 \times 4 \mathrm{~cm}, 250 \mathrm{~g}$ polycarbonate case, along with a charging circuit and a $16 \mathrm{~h}$, $2600 \mathrm{mAh}$ lithium-polymer battery, which was charged continuously from a USB cable supplying $5 \mathrm{~V}$ power. Manufacturer part identifiers and approximate costs for all components are listed in Table S1 in the Supplement; the physical design is shown in Fig. S1 in the Supplement. The components were easily procured from online electronics retailers with a total materials cost under USD 200 per PANDA. We estimate that a minimal variant, relying on a host device (e.g., a computer or phone) for power and data logging, could be constructed for less than USD 25 in electronic parts.

\subsection{Reference instruments}

Our primary standard was a Federal Equivalent Method (FEM) $\beta$-attenuation monitor (BAM-1020, Met One Instruments) that the Bay Area Air Quality Management District (AQMD) uses to monitor continuous $\mathrm{PM}_{2.5}$ mass concentrations. We downloaded $1 \mathrm{~h}$ FEM $\mathrm{PM}_{2.5}$ data reported by this instrument from the AQMD website. We also deployed our own commercially available optical instruments at the regulatory monitoring site: a 16-channel particle sizer (GRIMM OPC, Model 1.108, GRIMM); a nephelometer (DustTrak II 
model 8530 , TSI) equipped with a $2.5 \mu \mathrm{m}$ impactor and programmed with the default correction factor for ISO 12103$1 \mathrm{~A} 1$; and a consumer-oriented, laser-based optical particle counter (DC1700, Dylos Corp). These instruments are typical of those that would be used in a human exposure study, though the number that could be deployed would be greatly constrained by the per-unit cost. With the exception of the last, all of these instruments report data in $\mu \mathrm{g} \mathrm{m}^{-3}$ after using proprietary algorithms to filter and transform optical measurements into mass-concentration equivalents. Only the BAM-1020 and DustTrak have a physical size cut mechanism.

\subsection{Study location}

The Bay Area AQMD granted permission to co-locate our equipment at their West Oakland regulatory monitoring site in Oakland, California (Fig. S2 in the Supplement). We placed our instruments in two $30 \mathrm{~L}$ chambers (Fig. S3 in the Supplement) within $2 \mathrm{~m}$ of the inlet to the AQMD's $\beta$ attenuation monitor, approximately $5 \mathrm{~m}$ a.g.1., on the roof of an air-conditioned trailer in a parking lot, from 15 April 2013 to 23 April 2013.

West Oakland has previously been the subject of targeted air pollution modeling, emission inventories, mobile monitoring, saturation monitoring, and chemical speciation and source apportionment studies (Fujita and Campbell, 2010; Pingkuan, 2008; Reid, 2007; Fujita et al., 2013) as well as a locus for community-based participatory research concerning transportation-related emissions (Gonzalez et al., 2011). The West Oakland site is close to the Port of Oakland, the fourth largest container shipping port in the US, and proximate to considerable sources of truck and railroad diesel, as well as light-duty vehicle traffic on the Bay Bridge toll plaza and the surrounding freeways. The previous monitoring, speciation, and apportionment studies indicate that elemental carbon is concentrated near traffic routes, indicative of the influence of diesel truck traffic to primary PM, while organic carbon and $\mathrm{PM}_{2.5}$ exhibit a more uniform spatial distribution in the area, reflecting the importance of secondary aerosol formation and nitrate and sulfate particles (Fujita and Campbell, 2010; Fujita et al., 2013).

\subsection{Analytical methods}

Pairwise plots of data collected from the different instruments were augmented with loess smoothers and examined for linearity. To quantify and compare the strengths of correlations, we used the coefficients of determination $\left(R^{2}\right)$ from ordinary least-squares regression models fit to each pairwise data set. We also calculated empirical and simulated $R^{2}$ values for two BAM-1020s to provide perspective on the range of $R^{2}$ values expected with $1 \mathrm{~h}$ integration times. Root mean squared errors (RMSE) were computed to assess the accuracy of linear calibrations. We additionally conducted sensitivity analyses designed to assess the effects of temperature, relative humidity, and ambient light on instrument performance.

\section{Results}

\subsection{Time series at $1 \mathrm{~h}$ scale}

\subsubsection{Hourly PM concentrations}

Figure 1 shows time-series data from a range of instruments deployed during the 8-day interval in April 2013. Nighttime $\mathrm{PM}_{2.5}$ concentrations were higher than daytime concentrations, consistent with a nighttime descent of the boundary layer. Smaller ranges and means were seen in the first $48 \mathrm{~h}$. Concentrations reported by the DustTrak were consistently higher than $\beta$-attenuation measurements, which may be accounted for by the use of the default DustTrak correction factor. (This does not affect our primary statistic of interest, $R^{2}$.) Mass concentrations were also reported by the GRIMM OPC in size ranges from $0.3-30 \mu \mathrm{m}$. Since the GRIMM OPC does not report data corresponding exactly to $0<d_{\mathrm{p}}<2.5 \mu \mathrm{m}$ (i.e., $\mathrm{PM}_{2.5}$ ), Fig. 1 instead shows data for both $0.3<d_{\mathrm{p}}<3.0 \mu \mathrm{m}$ and $0.3<d_{\mathrm{p}}<2.0 \mu \mathrm{m}$. Number concentrations, as reported by the Dylos for "small" particles (approximately $0.3<d_{\mathrm{p}}<2.5 \mu \mathrm{m}$ ), also followed the same diurnal and synoptic patterns as the other instruments (Fig. 1).

\subsubsection{Hourly temperature, relative humidity, and ambient light}

The intake for our chamber was located within $2 \mathrm{~m}$ of the BAM-1020 intake. However, the electronics housed in our chamber contributed a small amount of excess heat, raising the temperature and lowering the relative humidity. Detailed temperature, relative humidity, and ambient light data are shown in Fig. S4 in the Supplement. Mean daily temperatures trended from approximately 20 to $30^{\circ} \mathrm{C}$, with diurnal variations of approximately $\pm 8^{\circ} \mathrm{C}$. Except for the $1 \mathrm{~h}$ period when we conducted a spot check and removed the chamber lid, ambient light remained below $1 \times 10^{1}$ lux. Relative humidity in the chamber ranged between 10 and $60 \%$ over the course of each day, well within the operating range of the PPD42NS and well under the $80 \%$ level at which lightscattering efficiency begins to substantially affect the quality of nephelometric measurements (Chow et al., 2002).

\subsection{Correlations at $1 \mathrm{~h}$ scale}

\subsubsection{Correlations between PANDAs and other optical instruments}

Figure 2 shows statistical and graphical summaries of pairwise correlations between $1 \mathrm{~h}$ data from all instruments. 


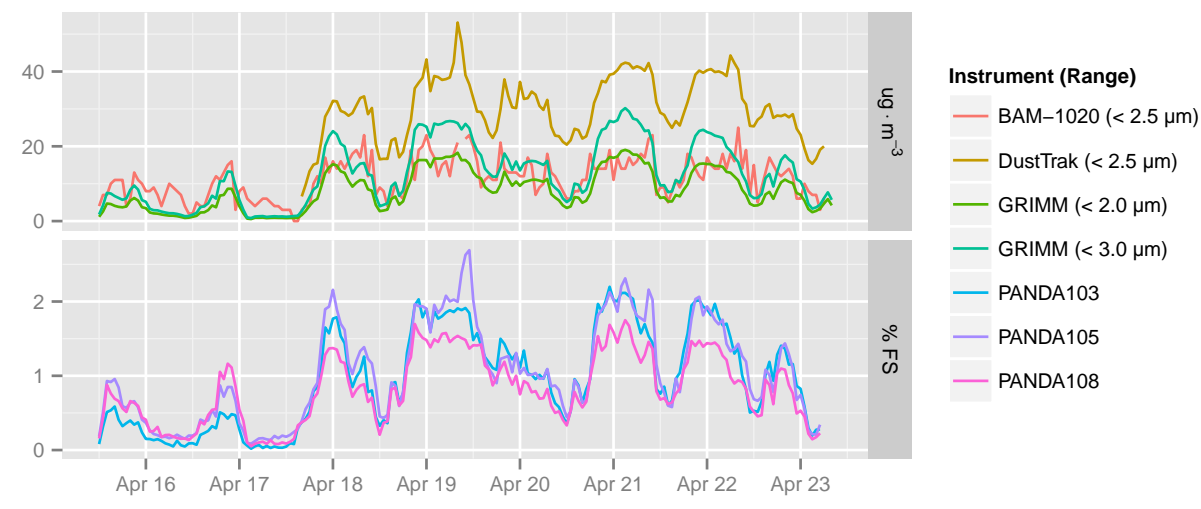

Fig. 1. Hourly data collected between 15 April 2013 and 23 April 2013 at the West Oakland regulatory monitoring site. Top panel: PM 2.5 measurements reported by BAM-1020, DustTrak, and GRIMM. Bottom panel: output (\% full scale) from three Shinyei PPD42NS sensors (see Table S1 and Figs. S1, S2, and S3 in the Supplement, for configuration details).

High correlations were found between individual PANDAs $\left(R^{2}=0.91-0.92\right)$ and between PANDAs and the Dy$\operatorname{los}\left(R^{2}=0.87-0.92\right)$. These data are consistent with previous pilot data from a 6-week experiment, in which we tested the longer-term stability and inter-device variability of PPD42NS sensors (see Figs. S5 and S6 in the Supplement). Correlations between PANDAs and GRIMM PM 2.0 and $\mathrm{PM}_{3.0}$ were high as well $\left(R^{2}=0.90-0.93\right.$ and $0.92-0.94$, respectively). Correlations of the DustTrak with the other optical instruments were more moderate $\left(R^{2}=0.64-0.80\right)$.

\subsubsection{Correlations of PANDAs and other optical instruments with the reference instrument (regulatory $\beta$-attenuation monitor)}

Using $1 \mathrm{~h} \beta$-attenuation data as a reference, coefficients of determination $\left(R^{2}\right)$ calculated for $1 \mathrm{~h}$ PANDAs, GRIMM $\mathrm{PM}_{2.0}$ and $\mathrm{PM}_{3.0}$, Dylos, and DustTrak data were 0.55-0.60; 0.59 and 0.58 ; 0.58; and 0.49, respectively (Fig. 2). The accuracies of linear models based on each device were essentially equal (RMSE $=3.4-3.6 ; 3.4$ and 3.5; 3.5; and $3.5 \mu \mathrm{g} \mathrm{m}^{-3}$, respectively). A slight non-linearity, common to all except the DustTrak, is suggested by the loess smoother superimposed on the lowest row of panels in Fig. 2.

At first glance, an $R^{2}$ of 0.55-0.60 may seem low, but it can be explained by the measurement error inherent in the reference instrument, which is specified as $\sigma=2.0-$ $2.4 \mu \mathrm{g} \mathrm{m}^{-3}$ for a $1 \mathrm{~h}$ integration time (Met One Instruments, n.d.). In a simulation, we used this $\sigma$ to generate paired observations of a "true" $\mathrm{PM}_{2.5}$ distribution with independent Gaussian errors, and calculated a range of expected $R^{2}$ estimates centered at 0.59 (95\% CI 0.50-0.67) (Fig. S7 in the Supplement). In other words, this is as correlated as one would expect $1 \mathrm{~h}$ measurements from two such reference instruments to be. Empirical data corroborated this expectation; although only one BAM-1020 is in operation at the West Oakland site, Fig. 3 shows 3 weeks of contemporaneous $1 \mathrm{~h}$ data from a pair of collocated BAM-1020s at a nearby Air
District site in Vallejo, $40 \mathrm{~km}$ away. The $R^{2}$ for these $1 \mathrm{~h} \beta$ attenuation measurements $\left(R^{2}=0.58\right)$ differs negligibly from (a) the simulated expectation, as well as the empirical $R^{2}$ between the BAM-1020 at West Oakland and (b) each of the three PANDAs, (c) the GRIMM, and (d) the Dylos. (The DustTrak exhibited slightly less agreement, $R^{2}=0.49$.)

\subsection{Effects of ambient light, temperature, and humidity}

We did not observe convincing associations with light $(L)$, temperature $(T)$, or relative humidity (RH). Tables 1a and $1 \mathrm{~b}$ show that neither $1 \mathrm{~h}$ data from the BAM nor $1 \mathrm{~h}$ data from the PANDAs could be explained by $L$ or $T$. Though $1 \mathrm{~h} \mathrm{RH}$ measurements had some ability to predict $1 \mathrm{~h}$ BAM responses $\left(R^{2}=0.24\right), 24 \mathrm{~h}$ averages did not $\left(R^{2}=0.02\right.$; see Sect. 3.5). This can be explained as a simple case of confounding at the $1 \mathrm{~h}$ timescale, rather than a causal association. Both $\mathrm{PM}_{2.5}$ and $\mathrm{RH}$ were elevated at night; moreover, since the intake air for the BAM-1020 is actively dried by heating, there is no mechanistic explanation for the observed association between $1 \mathrm{~h} \mathrm{RH}$ and $1 \mathrm{~h}$ BAM responses. Correlations of RH with PANDA responses at 1 and $24 \mathrm{~h}$ timescales were not appreciably different $\left(R^{2}=0.27\right.$ and 0.01 , respectively). Accordingly, we omitted $L, T$, and RH from subsequent models.

\subsection{Correlations at $24 \mathrm{~h}$ scale}

Following our initial observations with $1 \mathrm{~h}$ data, we conducted a longer-term deployment to examine $24 \mathrm{~h}$ averages (arithmetic means) at the same site from 1 August 2013 through 15 November 2013. Figure 4 shows a scatterplot of these $24 \mathrm{~h}$ data, superimposed by a linear regression fit by ordinary least squares. This linear model yielded an $R^{2}$ of 0.72 , an improvement compared to the $R^{2}$ of 0.60 found with $1 \mathrm{~h}$ data from the previous study (Sect. 3.2). 


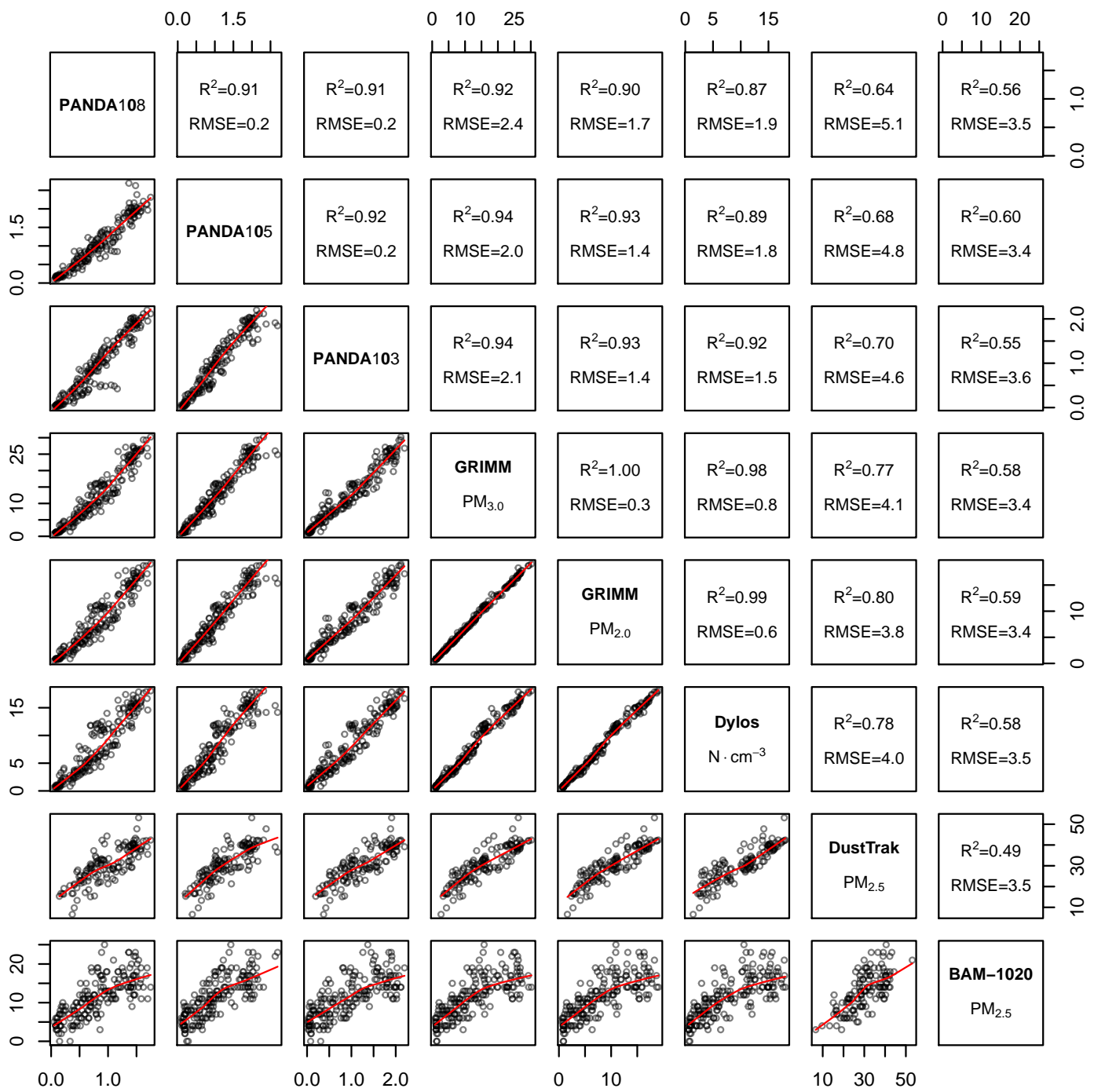

Fig. 2. Intercomparisons between hourly data from all instruments deployed at the West Oakland site from 15 April 2013 to 23 April 2013. Upper-right set of panels: $R^{2}$ and RMSE for linear models fit using ordinary least squares (OLS). Lower-left set of panels: loess smoothers superimposed on pairwise plots of the hourly data.

\section{Discussion}

\subsection{Findings}

Our overall objective was to determine whether a low-cost aerosol sensor like the PPD42NS could be used to generate adequately resolved measurements of urban $\mathrm{PM}_{2.5}$. Our first specific aim was to assess the utility of the PPD42NS by custom-building portable instruments (the PANDAs platform) and comparing them to commercially available optical instruments. Given the substantial differences in cost (material vs. retail), the agreement we observed between PANDAs and commercially available instruments was remarkably good (Figs. 1 and 2). In addition, PANDAs essentially matched the precision and accuracy $\left(R^{2}\right.$ and RMSE, respectively) of these more expensive instruments in predicting hourly $\mathrm{PM}_{2.5}$ from the reference instrument, a $\beta$-attenuation monitor (Fig. 2). While commercially available instruments may perform better in more extreme or varied environments, or in measuring other aerosols, or when faster response times are desired, within the context of our $1 \mathrm{~h}$ data we found little, if any, practical difference.

Conditional on the success of our first aim, our second aim was to use $24 \mathrm{~h} \mathrm{PM}_{2.5}$ data from our reference instrument (the Met One BAM-1020) to conduct a calibration over a longer period of time, on health-relevant scales. During our 3-month deployment, $24 \mathrm{~h}$ averages of reference measurements at the West Oakland site ranged from approximately 2 to $21 \mu \mathrm{g} \mathrm{m}^{-3}$ $\mathrm{PM}_{2.5}$, with a substantial amount of variability explained by a simple linear correction to the sensor data $\left(R^{2}=0.72\right)$. Obtaining this level of agreement with such a low-cost sensor suggests that, at least in urban areas with similar aerosols 

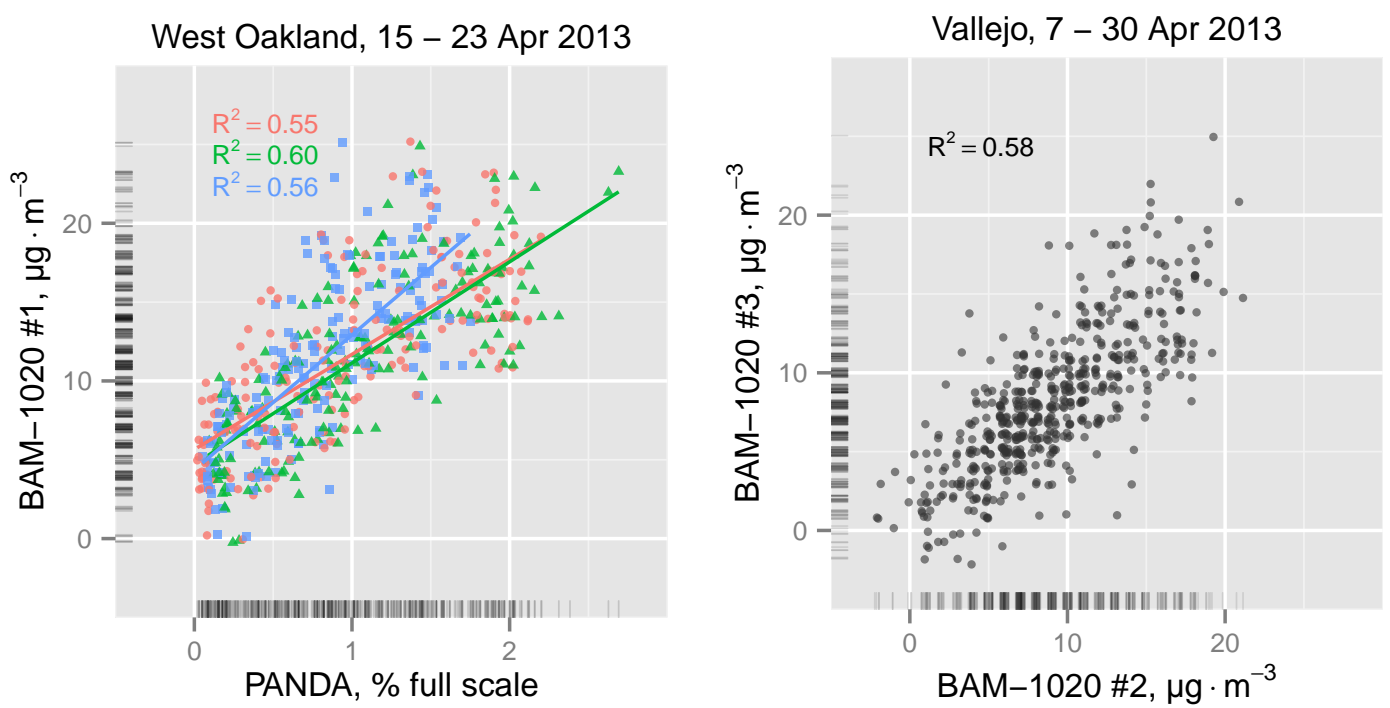

Fig. 3. Left panel: $1 \mathrm{~h}$ data collected between 15 and 23 April 2013 from three PANDAs and a reference $\left(\beta\right.$-attenuation) $\mathrm{PM}_{2.5}$ instrument at the regulatory monitoring site in Oakland. Right: approximately the same level of agreement $\left(R^{2} \approx 0.6\right)$ was found between $1 \mathrm{~h}$ data from a pair of $\beta$-attenuation instruments at a nearby regulatory monitoring site in Vallejo, California (40 km away), 7-30 April 2013. The original $1 \mathrm{~h}$ BAM data were available only at $1 \mu \mathrm{g} \mathrm{m}^{-3}$ resolution; points are jittered to reduce overplotting. Superimposed lines represent linear regressions of unjittered $1 \mathrm{~h}$ data.

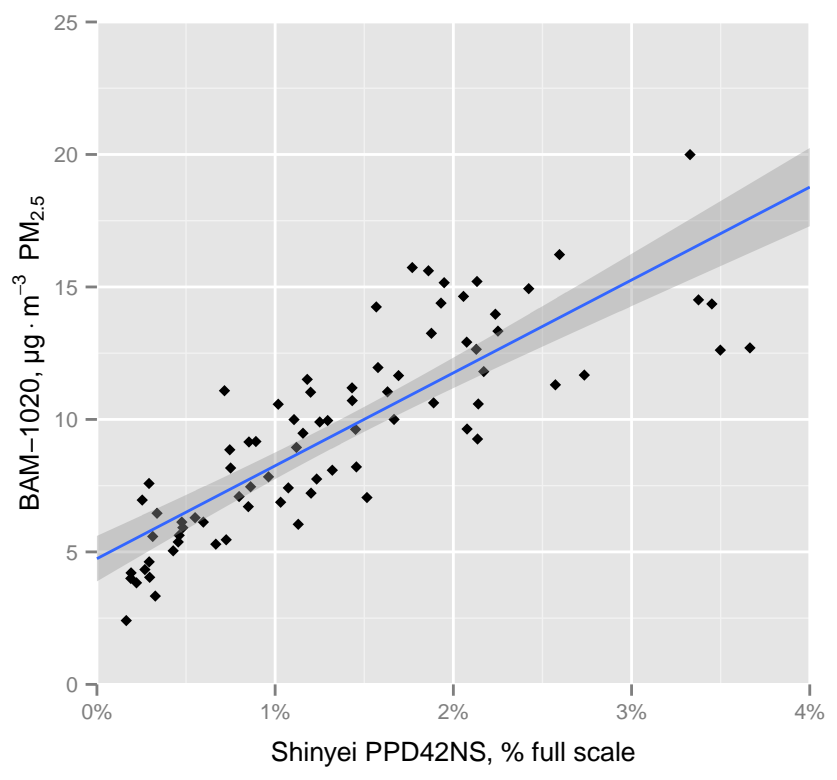

Fig. 4. $24 \mathrm{~h}$ arithmetic means of $1 \mathrm{~h}$ data collected between $1 \mathrm{Au}-$ gust 2013 and 15 November 2013 at the West Oakland site. The superimposed line and shading represents a linear regression, fit by ordinary least squares $\left(R^{2}=0.72\right)$, along with its $95 \%$ pointwise confidence intervals.

and concentrations, additional deployments and calibrations may help to usefully enhance the resolution of $\mathrm{PM}_{2.5}$ data sets. Moreover, the sensor's apparent effectiveness at resolving differences between relatively low $24 \mathrm{~h}$ concentrations suggests that it may be useful in more polluted regions, if can be shown to resist saturation and wear. For reference, the $24 \mathrm{~h}$ ambient $\mathrm{PM}_{2.5}$ concentration standard has been set by the US EPA (US EPA, 2012) at $35 \mu \mathrm{g} \mathrm{m}^{-3}$, while the World Health Organization has established a $24 \mathrm{~h}$ guideline (World Health Organization, 2005) of $25 \mu \mathrm{g} \mathrm{m}-3$. Annual standards/guidelines set by the US EPA, WHO, and EU are now 12,10 , and $25 \mathrm{~g} \mathrm{~m} \mathrm{~m}^{-3}$, respectively (European Union, 2008; US EPA, 2012; World Health Organization, 2005). Exceedances of these health-related benchmarks frequently occur in many populous cities and regions worldwide (Brauer et al., 2011).

\subsection{Limitations and tradeoffs}

Two major limitations are relevant to the aim of this work, in other words, increasing the availability of $\mathrm{PM}_{2.5}$ data through the use of lower-cost sensors. The first has to do with calibration requirements. In the US, the reference instrument we selected for calibration carries FEM (Federal Equivalent Method) status for $24 \mathrm{~h}$ measurements of $\mathrm{PM}_{2.5}$ (though not for $1 \mathrm{~h}$ measurements). Observational calibration, of the kind we employed, requires access to a site that is sufficiently close to such an instrument for a sufficient length of time; these parameters are conditional on the desired quality of the calibration, which is in turn conditional on the evidentiary standards that the resulting data need to meet. This kind of calibration has particular importance in the domain of $\mathrm{PM}_{2.5}$ measurement. While bottled standards are available to calibrate many gas instruments, the creation and circulation of $\mathrm{PM}_{2.5}$ transfer standards is problematic. The composition of $\mathrm{PM}_{2.5}$ is not universal, and it is impractical to create stable 
Table 1a. Adjusted $R^{2}$ for linear regressions of BAM $\left(\mathrm{PM}_{2.5} \mu \mathrm{g} \mathrm{m}^{-3}\right)$ on covariates. $L=$ light (lux), $T=$ temperature $\left({ }^{\circ} \mathrm{C}\right), \mathrm{RH}=$ relative humidity $(\%)$. Each PANDA has its own RH/T sensor. $R^{2}$ statistics were calculated on a per-PANDA basis (columns $2-4$ ) as well as for a "combined" model (column 5). The "combined" $R^{2}$ values are not the means of $R^{2}$ in columns 2-4, but were obtained by fitting the specified model form to the means of the regressands $(L, \mathrm{RH}$, or $T)$ averaged across all 3 PANDAs at each point in time.

\begin{tabular}{lcccc}
\hline Model & PANDA \#103 & PANDA \#105 & PANDA \#108 & Combined \\
\hline $\mathrm{BAM}=B_{0}+B_{1} \cdot L$ & 0.06 & 0.03 & 0.03 & 0.04 \\
$\mathrm{BAM}=B_{0}+B_{1} \cdot T$ & 0.02 & 0.02 & 0.03 & 0.02 \\
$\mathrm{BAM}=B_{0}+B_{1} \cdot \mathrm{RH}$ & 0.23 & 0.23 & 0.26 & 0.24 \\
\hline
\end{tabular}

Table 1b. Adjusted $R^{2}$ for linear regressions of Shinyei PPD42NS (\% full scale) on covariates.

\begin{tabular}{lcccc}
\hline Model & PANDA \#103 & PANDA \#105 & PANDA \#108 & Combined \\
\hline Shinyei $=B_{0}+B_{1} \cdot L$ & 0.02 & 0.01 & 0.00 & 0.01 \\
Shinyei $=B_{0}+B_{1} \cdot T$ & 0.01 & 0.01 & 0.02 & 0.01 \\
Shinyei $=B_{0}+B_{1} \cdot$ RH & 0.25 & 0.25 & 0.28 & 0.27 \\
\hline
\end{tabular}

Table 1c. Adjusted $R^{2}$ for linear regressions of BAM on Shinyei, with and without RH.

\begin{tabular}{lcccc}
\hline Model & PANDA \#103 & PANDA \#105 & PANDA \#108 & Combined \\
\hline BAM $=B_{0}+B_{1} \cdot$ Shinyei & 0.54 & 0.60 & 0.56 & 0.58 \\
BAM $=B_{0}+B_{1} \cdot$ Shinyei $+B_{2} \cdot$ RH & 0.56 & 0.61 & 0.58 & 0.59 \\
\hline
\end{tabular}

atmospheric suspensions of the $\mathrm{PM}_{2.5}$ mixtures to which urban populations are actually exposed. At the same time, the key parameters for calibration by co-location (closeness and duration) are bounded by serious practical and logistical constraints, including scarcities of time and trusted personnel. Working out these boundaries and relationships is an interesting and important task that is beyond the scope of this paper. For practical purposes, it seems possible that at least some professional air quality managers, urban planners, community-based organizations, and academics could coordinate co-location campaigns with relatively few resources, thereby developing calibration curves specific to neighborhoods and aerosols of interest.

The second limitation is intrinsic to the use of optical techniques as proxies for gravimetric measurements. When a difference in measured values is observed, one cannot be certain whether it is attributable to a difference in the total mass, size distribution, or optical properties - or some combination of all three - of the measured aerosols (Watson et al., 1998; Wilson et al., 2002). Conversely, a lack of difference can obscure real differences in submicron or ultrafine particle concentrations, or in other aerosol properties, such as composition or size distribution, that may have real toxicological significance (Lighty et al., 2000; Wilson and Suh, 1997). Ambient aerosols typically have a trimodal size distribution, with a certain proportion of the respirable mass, and a much higher proportion of the total count, distributed in such submicron or "accumulation-mode" particles (John,
2011; Whitby, 1978). In urban atmospheres, these particles can generally be traced to emissions from internal combustion engines. They are more likely to deposit in the deep lungs or be absorbed through the nasal cavity, and are thus of considerable public health concern (Lighty et al., 2000). The error from these technical limitations can be approximately bounded, however, and a rough $95 \%$ bound on the uncertainty associated with nephelometric estimates of $\mathrm{PM}_{2.5}$ has been estimated (Molenar, 2014) as $\pm 40 \%$, close to that associated with replicate gravimetric analyses (Lighty et al., 2000).

Continuing work with more sensors under varying environmental and experimental conditions will be needed to more precisely characterize the influence of variations between low-cost optical aerosol sensors, aerosols, and operating conditions. However, it is instructive to compare the expected magnitude cited above $( \pm 40 \%)$ with the specified variance of the $\beta$-attenuation method $\left(2 \sigma=4.0-4.8 \mu \mathrm{g} \mathrm{m}^{-3}\right.$ for $1 \mathrm{~h}$ integration times) and the accuracy of our predictive $\mathrm{PM}_{2.5}$ models $\left(\mathrm{RMSE}=3.4-3.6 \mu \mathrm{g} \mathrm{m}^{-3}\right.$, again for $1 \mathrm{~h}$ estimates). When true concentrations are in the range of 2 $25 \mathrm{~g} \mathrm{~m} \mathrm{~m}^{-3}$, then in absolute terms these errors are roughly comparable. More importantly, measurement error of 1$10 \mu \mathrm{g} \mathrm{m}^{-3}$ may be much less than the error associated with interpolations of sparse data from a few expensive instruments. This leads to the consideration of tradeoffs in methodology - or, from a complementary perspective, to the optimal 
design of hybrid approaches (National Research Council, 2012).

For exposure scientists, a larger number of less precise instruments may be especially useful in studies where both intra-subject and between-subject variability cannot be adequately sampled with a smaller number of higher-quality monitors, for example in monitoring household kitchens burning solid fuels (McCracken et al., 2009). In community monitoring or near-roadway contexts, a dense network or gradient with deliberate oversampling could provide highquality estimates of spatiotemporally resolved concentrations. More flexible saturation monitoring, based on less expensive and more portable instruments, could also respond more readily to changing land use, enable more timely empirical verifications of emission-reduction policies, facilitate rapid responses to natural or accidental releases of observed aerosols, and support more efficient screening campaigns for urban "hot spots", with follow-up measurements made by reference techniques.

\section{Future work and conclusion}

The next steps of our work involve the continuing deployment of a larger number of aerosol sensors within the context of an established neighborhood-scale multi-pollutant network in the Bay Area (Teige et al., 2011), the coverage of which overlaps with neighborhoods identified by the Bay Area AQMD over the past decade as having high levels of air pollution and vulnerable populations (BAAQMD, 2014). It complements efforts by other scientists to develop and refine emission inventories, screening methods, and exposure assessments. It is also germane to the relatively new phenomenon of "citizen scientists" constructing and using their own low-cost air pollution instrumentation (Demuth et al., 2013; Smith and Clark, 2014) as well as to recent efforts to support this kind of innovation and to integrate it with established pollutant monitoring infrastructures (CITI-SENSE, 2014; US EPA, 2013). It is informed by the work of research engineers in related fields, including atmospheric science (Mead et al., 2013; Teige et al., 2011), networked sensor calibration (Hasenfratz et al., 2012; Balzano, 2007; Xiang et al., 2012) and mobile/participatory air quality sensing (Aoki et al., 2009; DiSalvo et al., 2012; Dutta et al., 2009; Honicky et al., 2008; Jiang et al., 2011; Mun et al., 2009; Nikzad et al., 2012; Paulos et al., 2007; Willett et al., 2010; Zappi et al., 2012). Finally, it suggests new prospects for collaborative environmental health research with community residents. Community-engaged participatory research projects have deployed fixed-site monitors (Brugge et al., 2010; Hedges, 2002; Loh et al., 2002) and surveyed intra-urban variations in $\mathrm{PM}_{2.5}$ using portable nephelometers (Kinney et al., 2000; Pastor Jr. et al., 2010). Our data indicate that device-specific and site-specific calibrations may help low-cost sensors yield data of comparable quality. To increase the value of collected data, protocols for calibration might be profitably incorporated into research on user interfaces and scaffolding (Willett et al., 2010) for non-professional users and groups interested in gathering, organizing, and collectively interpreting localized air quality measurements.

Despite their limitations, trends in the development and deployment of low-cost air pollution monitoring technologies are likely to continue (Snyder et al., 2013). A significant but little-explored vein of research concerns the impacts that a proliferation of low-cost air quality instrumentation will have on structures of participation in air pollution monitoring and air quality management (cf. Harrison, 2011; Ottinger, 2009). Although collaborations between new and established stakeholders may improve mutual awareness and engagement, the manner in which new monitoring data generated from low-cost instrumentation should be incorporated into regulatory decision-making remains an important open question.

\section{Supplementary material related to this article is available online at http://www.atmos-meas-tech.net/7/ 1121/2014/amt-7-1121-2014-supplement.pdf.}

Acknowledgements. We gratefully acknowledge the SF Bay Area AQMD and UC Berkeley CITRIS for their institutional support of this work, and thank Phil Martien, Virginia Lau, Glen Colwell, and Rob Schusteritsch for generously facilitating access to the West Oakland monitoring site. Kathie Hammond and Michael Jerrett graciously loaned us equipment and facilities. Tracy Allen, a longtime expert in low-cost sensing, has been a steady source of insight and advice. We are also indebted to Chris Nafis, who originally called attention to the prospects of the Shinyei PPD42NS via blog posts and public correspondence. Early development and pilot studies benefited from the diligent work of Ben Weia, a visiting undergraduate from Rice University. Finally, we are grateful to Hilary Ong, who put prototypes through extensive trials, and to the volunteers who assembled PANDAs: Aaron Bestick, Dave Bauer, Victor Shia, Posu Yan, Daniel Wu, Cristen Torrey, Eunice Lee, Nick Lam, Amanda Northcross, Hilary Ong, and Drew Hill. Helpful comments on initial drafts were provided by Anna Mebust, Benjamin Nault, Holly Maness, Andrew Hooker, Jill Teige, Ron Cohen and Rachel Morello-Frosch.

All the authors have seen and approved the manuscript and declare no conflict of interest. No compensation or incentives have been furnished by the manufacturers or distributors of any reference equipment or any components of our instrumentation.

Edited by: G. Phillips 


\section{References}

Aoki, P. M., Honicky, R. J., Mainwaring, A., Myers, C., Paulos, E., Subramanian, S., and Woodruff, A.: A Vehicle for Research: Using Street Sweepers to Explore the Landscape of Environmental Community Action, CHI 2009, Boston, Massachusetts, USA, 2009.

Bay Area Air Quality Management District - BAAQMD: The Community Air Risk Evaluation (CARE) program, available at: http://www.baaqmd.gov/Divisions/Planning-and-Research/ CARE-Program.aspx, last access: 26 April 2014.

Balzano, L.: Addressing fault and calibration in wireless sensor networks, University of California, Los Angeles, 2007.

Brauer, M., Amann, M., Burnett, R. T., Cohen, A., Dentener, F., Ezzati, M., Henderson, S. B., Krzyzanowski, M., Martin, R. V., Van Dingenen, R., van Donkelaar, A., and Thurston, G. D.: Exposure assessment for estimation of the global burden of disease attributable to outdoor air pollution, Environ. Sci. Technol., 46, 652-660, doi:10.1021/es2025752, 2011.

Brugge, D., Rivera-Carrasco, E., Zotter, J., and Leung, A.: Community-based participatory research in Boston's neighborhoods: a review of asthma case examples, Arch. Environ. Occup. H., 65, 38-44, doi:10.1080/19338240903390214, 2010.

Budde, M., Busse, M., and Beigl, M.: Investigating the use of commodity dust sensors for the embedded measurement of particulate matter, Ninth International Conference on Networked Sensing Systems (INSS), Antwerp, Belgium, 2012.

Burkart, J., Steiner, G., Reischl, G., Moshammer, H., Neuberger, M., and Hitzenberger, R.: Characterizing the performance of two optical particle counters (Grimm OPC1.108 and OPC1.109) under urban aerosol conditions, J. Aerosol Sci., 41, 953-962, doi:10.1016/j.jaerosci.2010.07.007, 2010.

Chow, J. C., Engelbrecht, J. P., Watson, J. G., Wilson, W. E., Frank, N. H., and Zhu, T.: Designing monitoring networks to represent outdoor human exposure, Chemosphere, 49, 961-978, 2002

Chowdhury, Z., Edwards, R. D., Johnson, M., Naumoff Shields, K., Allen, T., Canuz, E., and Smith, K. R.: An inexpensive lightscattering particle monitor: field validation, J. Environ. Monitor., 9, 1099-1106, doi:10.1039/b709329m, 2007.

CITI-SENSE: Development of sensor-based Citizens' Observatory Community for improving quality of life in cities, 7th EC RTD Framework Program, contract No. 308524, aqvailable at: http: //www.citi-sense.eu/, last access: 26 April 2014.

Demuth, D., Nuest, D., Bröring, A., and Pebesma, E.: The AirQuality SenseBox, EGU General Assembly Conference Abstracts, Vol. 15, p. 5146, 2013.

DiSalvo, C., Louw, M., Holstius, D., Nourbakhsh, I., and Akin, A.: Toward a public rhetoric through participatory design: critical engagements and creative expression in the Neighborhood Networks Project, Des. Issues, 28, 48-61, doi:10.1162/DESI_a_00161, 2012.

Dutta, P., Aoki, P. M., Kumar, N., Mainwaring, A., Myers, C., Willett, W., and Woodruff, A.: Common Sense: Participatory urban sensing using a network of handheld air quality monitors, ACM Conference on Embedded Networked Sensor Systems, Berkeley, CA, 2009.
Edwards, R. D., Smith, K. R., Kirby, B., Allen, T., Litton, C. D., and Hering, S.: An inexpensive dual-chamber particle monitor: laboratory characterization, J. Air Waste Manage., 56, 789-799, 2006.

European Union: Directive 2008/50/EC of the European Parliament and of the Council of 21 May 2008 on ambient air quality and cleaner air for Europe, Brussels, Belgium, 1-44, 2008.

Fujita, E. M. and Campbell, D.: West Oakland Monitoring Study, Desert Research Institute, Reno, NV, 1-115, 2010.

Fujita, E. M., Campbell, D. E., Patrick Arnott, W., Lau, V., and Martien, P. T.: Spatial variations of particulate matter and air toxics in communities adjacent to the Port of Oakland, J. Air Waste Manage., 63, 1399-1411, doi:10.1080/10962247.2013.824393, 2013.

Gonzalez, P., Minkler, M., Garcia, A., Gordon, M., Garzón, C., Palaniappan, M., Prakash, S., and Beveridge, B.: Communitybased participatory research and policy advocacy to reduce diesel exposure in West Oakland, California, Am. J. Public Health, 101, S166-S175, doi:10.2105/AJPH.2010.196204, 2011.

Harrison, J. L.: Parsing "participation" in action research: navigating the challenges of lay involvement in technically complex participatory science projects, Soc. Natur. Resour., 24, 702-716, doi:10.1080/08941920903403115, 2011.

Hasenfratz, D., Saukh, O., and Thiele, L.: On-the-fly calibration of low-cost gas sensors, Conference on Wireless Sensor Networks (EWSN), Springer, Berlin, Heidelberg, 228-244, 2012.

Hedges, S.: Planning and implementing a real-time air pollution monitoring and outreach program for your community, US EPA National Risk Management Research Laboratory, Cincinnati, OH, 2002.

Honicky, R., Brewer, E., Paulos, E., and White, R.: N-smarts: networked suite of mobile atmospheric real-time sensors, ACM SIGCOMM workshop on Networked systems for developing regions, 2008.

Jerrett, M., Arain, A., Kanaroglou, P., Beckerman, B., Potoglou, D., Sahsuvaroglu, T., Morrison, J., and Giovis, C.: A review and evaluation of intraurban air pollution exposure models, J. Expo. Anal. Env. Epid., 15, 185-204, 2005.

Jiang, Y., Li, K., Tian, L., Piedrahita, R., Yun, X., Mansata, O., Lv, Q., Dick, R. P., Hannigan, M., and Shang, L.: MAQS: A Personalized Mobile Sensing System for Indoor Air Quality Monitoring. Proceedings of the 13th International Conference on Ubiquitous Computing, Beijing, 271-280, 2011.

John, W.: Size distribution characteristics of aerosols, in: Aerosol Measurement: Principles, Techniques, and Applications, 3rd Edn., edited by: Kulkarni, P., Baron, P. A., and Willeke, K., John Wiley and Sons, New York, 41-54, 2011.

Kinney, P. L., Aggarwal, M., Northridge, M. E., Janssen, N. A., and Shepard, P. M.: Airborne concentrations of $\mathrm{PM}_{2.5}$ and diesel exhaust particles on Harlem sidewalks: a community-based pilot study, Environ. Health Persp., 108, 213-218, 2000.

Lighty, J. S., Veranth, J. M., and Sarofim, A. F.: Combustion aerosols: factors governing their size and composition and implications to human health, J. Air Waste Manage., 50, 1522-1565, 2000.

Lim, S. S., Vos, T., Flaxman, A. D., Danaei, G., Shibuya, K., AdairRohani, H., AlMazroa, M. A., Amann, M., Anderson, H. R., Andrews, K. G., Aryee, M., Atkinson, C., Bacchus, L. J., Bahalim, A. N., Balakrishnan, K., Balmes, J., Barker-Collo, S., Baxter, A., Bell, M. L., Blore, J. D., Blyth, F., Bonner, C., Borges, G., 
Bourne, R., Boussinesq, M., Brauer, M., Brooks, P., Bruce, N. G., Brunekreef, B., Bryan-Hancock, C., Bucello, C., Buchbinder, R., Bull, F., Burnett, R. T., Byers, T. E., Calabria, B., Carapetis, J., Carnahan, E., Chafe, Z., Charlson, F., Chen, H., Chen, J. S., Cheng, A. T.-A., Child, J. C., Cohen, A., Colson, K. E., Cowie, B. C., Darby, S., Darling, S., Davis, A., Degenhardt, L., Dentener, F., Des Jarlais, D. C., Devries, K., Dherani, M., Ding, E. L., Dorsey, E. R., Driscoll, T., Edmond, K., Ali, S. E., Engell, R. E., Erwin, P. J., Fahimi, S., Falder, G., Farzadfar, F., Ferrari, A., Finucane, M. M., Flaxman, S., Fowkes, F. G. R., Freedman, G., Freeman, M. K., Gakidou, E., Ghosh, S., Giovannucci, E., Gmel, G., Graham, K., Grainger, R., Grant, B., Gunnell, D., Gutierrez, H. R., Hall, W., Hoek, H. W., Hogan, A., Hosgood III, H. D., Hoy, D., Hu, H., Hubbell, B. J., Hutchings, S. J., Ibeanusi, S. E., Jacklyn, G. L., Jasrasaria, R., Jonas, J. B., Kan, H., Kanis, J. A., Kassebaum, N., Kawakami, N., Khang, Y.-H., Khatibzadeh, S., Khoo, J.-P., Kok, C., Laden, F., Lalloo, R., Lan, Q., Lathlean, T., Leasher, J. L., Leigh, J., Li, Y., Lin, J. K., Lipshultz, S. E., London, S., Lozano, R., Lu, Y., Mak, J., Malekzadeh, R., Mallinger, L., Marcenes, W., March, L., Marks, R., Martin, R., McGale, P., McGrath, J., Mehta, S., Memish, Z. A., Mensah, G. A., Merriman, T. R., Micha, R., Michaud, C., Mishra, V., Hanafiah, K. M., Mokdad, A. A., Morawska, L., Mozaffarian, D., Murphy, T., Naghavi, M., Neal, B., Nelson, P. K., Nolla, J. M., Norman, R., Olives, C., Omer, S. B., Orchard, J., Osborne, R., Ostro, B., Page, A., Pandey, K. D., Parry, C. D. H., Passmore, E., Patra, J., Pearce, N., Pelizzari, P. M., Petupta, M., Phillips, M. R., Pope, D., Pope III, C. D., Powles, J., Rao, M., Razavi, H., Rehfuess, E. A., Rehm, J. T., Ritz, B., Rivara, F. P., Roberts, T., Robinson, C., Rodriguez-Portales, J. A., Romieu, I., Room, R., Rosenfeld, L. C., Roy, A., Rushton, L., Salomon, J. A., Sampson, U., Sanchez-Riera, L., Sanman, E., Sapkota, A., Seedat, S., Shi, P., Shield, K., Shivakoti, R., Singh, G. M., Sleet, D. A., Smith, E., Smith, K. R., Stapelberg, N. J. C., Steenland, K., Stöckl, H., Stovner, L. J., Straif, K., Straney, L., Thurston, G. D., Tran, J. H., Van Dingenen, R., van Donkelaar, A., Veerman, J. L., Vijayakumar, L., Weintraub, R., Weissman, M. M., White, R. A., Whiteford, H., Wiersma, S. T., Wilkinson, J. D., Williams, H. C., Williams, W., Wilson, N., Woolf, A. D., Yip, P., Zielinski, J. M., Lopez, A. D., Murray, C. J. L., and Ezzati, M.: A comparative risk assessment of burden of disease and injury attributable to 67 risk factors and risk factor clusters in 21 regions, 19902010: a systematic analysis for the Global Burden of Disease Study 2010, Lancet, 380, 2224-2260, 2012.

Litton, C. D., Smith, K. R., Edwards, R., and Allen, T.: Combined optical and ionization measurement techniques for inexpensive characterization of micrometer and submicrometer aerosols, Aerosol Sci. Tech., 38, 1054-1062, doi:10.1080/027868290883333, 2004.

Loh, P., Sugerman-Brozan, J., Wiggins, S., Noiles, D., and Archibald, C.: From asthma to AirBeat: community-driven monitoring of fine particles and black carbon in Roxbury, Massachusetts, Environ. Health Persp., 110, 297-301, 2002.

McCracken, J. P., Schwartz, J., Bruce, N., Mittleman, M., Ryan, L. M., and Smith, K. R.: Combining individual- and group-level exposure information: child carbon monoxide in the Guatemala woodstove randomized control trial, Epidemiology, 20, 127-136, doi:10.1097/EDE.0b013e31818ef327, 2009.
Mead, M. I., Popoola, O. A. M., Stewart, G. B., Landshoff, P., Calleja, M., Hayes, M., Baldovi, J. J., McLeod, M. W., Hodgson, T. F., Dicks, J., Lewis, A., Cohen, J., Baron, R., Saffell, J. R., and Jones, R. L.: The use of electrochemical sensors for monitoring urban air quality in low-cost, high-density networks, Atmos. Environ., 70, 186-203, doi:10.1016/j.atmosenv.2012.11.060, 2013.

Molenar, J. V.: Theoretical analysis of $\mathrm{PM}_{2.5}$ mass measurements by nephelometry, IMPROVE Project, available at: http://vista.cira.colostate.edu/improve/publications/graylit/014_ AerosolByNeph/AerosolbyNeph.pdf, last access: 26 April 2014.

Mun, M., Reddy, S., Shilton, K., Yau, N., Burke, J., Estrin, D., Hansen, M., Howard, E., West, R., and Boda, P.: PEIR, the personal environmental impact report, as a platform for participatory sensing systems research, Proceedings of the 7th international conference on mobile systems, applications, and services, 22-25 June 2009, Kraków, Poland, 55-68, 2009.

Nafis, C.: Automatically measuring and graphing air quality with an inexpensive device, available at: http://www.howmuchsnow. com/ arduino/airquality/, last access: 1 October 2012.

National Research Council: Exposure Science in the 21st Century: a Vision and a Strategy, The National Academies Press, Washington, D.C., 2012.

Nikzad, N., Verma, N., Ziftci, C., Bales, E., Quick, N., Zappi, P., Patrick, K., Dasgupta, S., Krueger, I., Rosing, T. Š., and Griswold, W. G.: CitiSense: Improving Geospatial Environmental Assessment of Air Quality Using a Wireless Personal Exposure Monitoring System, Proceedings of the International Conference on Wireless Health, San Diego, CA, 2012.

Northcross, A. L., Edwards, R. J., Johnson, M. A., Wang, Z.-M., Zhu, K., Allen, T., and Smith, K. R.: A low-cost particle counter as a realtime fine-particle mass monitor, Environ. Sci. Process. Impact., 15, 433-439, doi:10.1039/c2em30568b, 2013.

Olivares, G., Longley, I., and Coulson, G.: Development of a LowCost Device for Observing Indoor Particle Levels Associated with Source Activities in the Home, International Society of Exposure Science (ISES), Seattle, WA, 2012.

Ottinger, G.: Epistemic fencelines: air monitoring instruments and expert-resident boundaries, Spontaneous Generations, 3, 55-67, doi:10.4245/sponge.v3i1.6115, 2009

Pastor Jr., M., Morello-Frosch, R., and Sadd, J. L.: Air Pollution and Environmental Justice: Integrating Indicators of Cumulative Impact and Socio-Economic Vulnerability into Regulatory Decision-Making, Report No. 04-308, California Air Resources Board, Sacramento, CA, 2010.

Paulos, E., Honicky, R. J., and Goodman, E.: Sensing Atmosphere, ACM Conference on Embedded Networked Sensor Systems (SenSys), 6-9 November 2007, Sydney, Australia, 2007.

Pingkuan, D.: Diesel Particulate Matter Health Risk Assessment for the West Oakland Community, California Air Resources Board, Sacramento, CA, 2008.

Reid, S. B.: Documentation of emission estimation techniques for sources of diesel particulate matter (DPM) associated with truckbased businesses and construction projects in West Oakland, California, Contract No. 2006-144, STI-907006-3174-TM, Sonoma Technology, Petaluma, CA, 2007.

Shinyei Corp.: Specification Sheet of Particle Sensor Model PPD42NS, available at: http://www.sca-shinyei.com/pdf/ PPD42NS.pdf (last access: 17 January 2014), 2010. 
Smith, K. R.: Development of the UCB-L Particle Monitor for Future California Applications in Environmental Justice, University of California, Berkeley, 2011.

Smith, P. A. and Clark, M.: Microsampling Air Pollution, The New York Times, p. D4, New York, available at: http://well.blogs. nytimes.com/2013/06/03/microsampling-air-pollution/, last access: 26 April 2014

Snyder, E. G., Watkins, T. H., Solomon, P. A., Thoma, E. D., Williams, R. W., Hagler, G. S. W., Shelow, D., Hindin, D. A., Kilaru, V. J., and Preuss, P. W.: The changing paradigm of air pollution monitoring, Environ. Sci. Technol., 47, 11369-11377, 2013.

Teige, V. E., Havel, E., Patt, C., Heber, E., and Cohen, R. C.: Berkeley Atmospheric $\mathrm{CO}_{2}$ Network (BEACON): Bringing Measurements of $\mathrm{CO}_{2}$ Emissions to a School Near You, Abstract \#ED53C-0814, Fall Meeting, American Geophysical Union, San Francisco, CA, 2011.

US EPA: National Ambient Air Quality Standards for Particulate Matter: Final Rule, Federal Register, Vol. 78, Part II: 40 CFR Parts 50, 51, 52 et al., Washington, D.C., 2012.

US EPA: Next Generation Air Monitoring Workshop Series, Air Sensors 2013: Data Quality \& Applications, Research Triangle Park, NC, 2013.

Watson, J. G.: Visibility: science and regulation, J. Air Waste Manage., 52, 628-713, 2002.

Watson, J. G., Chow, J. C., Moosmüller, H., Green, M., Frank, N., and Pitchford, M.: Guidance for using continuous monitors in $\mathrm{PM}_{2.5}$ monitoring networks, Report no. EPA-454/R-98-012, US EPA Office of Air Quality Planning and Standards, Research Triangle Park, NC, 1998.
Whitby, K. T.: The physical characteristics of sulfur aerosols, Atmos. Environ., 12, 135-159, 1978.

Willett, W., Aoki, P. M., Kumar, N., and Subramanian, S.: Common Sense Community: scaffolding mobile sensing and analysis for novice users, in: Pervasive Computing, Springer, Berlin, Heidelberg, 301-318, 2010.

Wilson, J. G., Kingham, S., Pearce, J., and Sturman, A. P.: A review of intraurban variations in particulate air pollution: implications for epidemiological research, Atmos. Environ., 39, 6444-6462, doi:10.1016/j.atmosenv.2005.07.030, 2005.

Wilson, W. E. and Suh, H. H.: Fine particles and coarse particles: concentration relationships relevant to epidemiologic studies, J. Air Waste Manage., 47, 1238-1249, 1997.

Wilson, W. E., Chow, J. C., Claiborn, C., Fusheng, W., Engelbrecht, J., and Watson, J. G.: Monitoring of particulate matter outdoors, Chemosphere, 49, 1009-1043, 2002.

World Health Organization: WHO Air Quality Guidelines Global Update 2005: Report on a Working Group Meeting, 18-20 October 2005, Bonn, Germany, 2005.

Xiang, Y., Bai, L. S., Piedrahita, R., and Arbor, A.: Collaborative Calibration and Sensor Placement for Mobile Sensor Networks, The 11th ACM/IEEE Conference on Information Processing in Sensor Networks, 16-19 April 2012, Beijing, 2012.

Zappi, P., Bales, E., Park, J. H., Griswold, W., and Rosing, T. Š.: The CitiSense Air Quality Monitoring Mobile Sensor Node, IPSN Workshop on Mobile Sensing, Bejing, China, 2012. 